\title{
A Randomized, Controlled Trial of Magnesium Sulfate for the Prevention of Cerebral Palsy
}

\begin{abstract}
Dwight J. Rouse, M.D., Deborah G. Hirtz, M.D., Elizabeth Thom, Ph.D., Michael W. Varner, M.D., Catherine Y. Spong, M.D., Brian M. Mercer, M.D., Jay D. lams, M.D., Ronald J. Wapner, M.D., Yoram Sorokin, M.D., James M. Alexander, M.D., Margaret Harper, M.D., John M. Thorp Jr., M.D., Susan M. Ramin, M.D., Fergal D. Malone, M.D., Marshall Carpenter, M.D., Menachem Miodovnik, M.D., Atef Moawad, M.D., Mary J. O'Sullivan, M.D., Alan M. Peaceman, M.D., Gary D.V. Hankins, M.D., Oded Langer, M.D., Steve N. Caritis, M.D., James M. Roberts, M.D., and the Eunice Kennedy Shriver NICHD Maternal-Fetal Medicine Units Network ${ }^{\star}$

University of Alabama at Birmingham, Birmingham (D.J.R.); National Institute of Neurological Disorders and Stroke, Bethesda, MD (D.G.H.); George Washington University Biostatistics Center, Washington, DC (E.T.); University of Utah, Salt Lake City (M.W.V.); National Institute of Child Health and Human Development, Bethesda, MD (C.Y.S.); Case Western Reserve University, Cleveland, and University of Tennessee, Memphis (B.M.M.); Ohio State University, Columbus (J.D.I.); Thomas Jefferson University and Drexel University — both in Philadelphia (R.J.W.); Wayne State University, Detroit (Y.S.); University of Texas Southwestern Medical Center, Dallas (J.M.A.); Wake Forest University, Winston-Salem, NC (M.H.); University of North Carolina, Chapel Hill (J.M.T.); University of Texas at Houston, Houston (S.M.R.); Columbia University, New York (F.D.M.); Brown University, Providence, RI (M.C.); University of Cincinnati, Cincinnati (M.M.); University of Chicago, Chicago (A.M.); University of Miami, Miami (M.J.O.); Northwestern University, Chicago (A.M.P.); University of Texas Medical Branch, Galveston (G.D.V.H.); University of Texas at San Antonio, San Antonio (O.L.); and University of Pittsburgh, Pittsburgh (S.N.C., J.M.R.).
\end{abstract}

\section{Abstract}

BACKGROUND—Research suggests that fetal exposure to magnesium sulfate before preterm birth might reduce the risk of cerebral palsy.

\begin{abstract}
METHODS-In this multicenter, placebo-controlled, double-blind trial, we randomly assigned women at imminent risk for delivery between 24 and 31 weeks of gestation to receive magnesium sulfate, administered intravenously as a 6-g bolus followed by a constant infusion of $2 \mathrm{~g}$ per hour, or matching placebo. The primary outcome was the composite of stillbirth or infant death by 1 year of corrected age or moderate or severe cerebral palsy at or beyond 2 years of corrected age.
\end{abstract}

RESULTS-A total of 2241 women underwent randomization. The baseline characteristics were similar in the two groups. Follow-up was achieved for $95.6 \%$ of the children. The rate of the primary outcome was not significantly different in the magnesium sulfate group and the placebo group $(11.3 \%$ and $11.7 \%$, respectively; relative risk, $0.97 ; 95 \%$ confidence interval [CI], 0.77 to 1.23 ). However, in a prespecified secondary analysis, moderate or severe cerebral palsy occurred significantly less frequently in the magnesium sulfate group ( $1.9 \%$ vs. $3.5 \%$; relative risk, $0.55 ; 95 \% \mathrm{CI}, 0.32$ to 0.95$)$.

Copyright @ 2008 Massachusetts Medical Society.

Address reprint requests to Dr. Rouse at OHB 457, 619 19th St. S., Birmingham, AL 35249-7333, or at drouse@uab.edu..

The other members of the Eunice Kennedy Shriver National Institute of Child Health and Human Development (NICHD) Maternal-

Fetal Medicine Units Network are listed in the Appendix.

Presented in part at the 28th annual meeting of the Society for Maternal-Fetal Medicine, Dallas, January 31-February 2, 2008.

No potential conflict of interest relevant to this article was reported. 
The risk of death did not differ significantly between the groups ( $9.5 \%$ vs. $8.5 \%$; relative risk, 1.12 ; $95 \%$ CI, 0.85 to 1.47$)$. No woman had a life-threatening event.

CONCLUSIONS-Fetal exposure to magnesium sulfate before anticipated early preterm delivery did not reduce the combined risk of moderate or severe cerebral palsy or death, although the rate of cerebral palsy was reduced among survivors. (ClinicalTrials.gov number, NCT00014989.)

CEREBRAL PALSY IS CHARACTERIZED BY abnormal control of movement and posture that results in limitation of activity. It is caused by nonprogressive damage or dysfunction of the developing fetal or infant brain ${ }^{1}$ and is a leading cause of chronic childhood disability, with profound medical, emotional, and economic consequences. ${ }^{2}$ Preterm birth is a risk factor for cerebral palsy, and the magnitude of the risk is inversely correlated with gestational age at birth. ${ }^{3}$ During the past 20 to 30 years, the survival of infants born markedly preterm has improved dramatically, and whereas some data suggest that the rate of cerebral palsy among survivors has recently declined, ${ }^{4}$ other data suggest that the rate is unchanged ${ }^{5}$ or even increasing. ${ }^{6}$ At present, approximately one third of cases of cerebral palsy are associated with early preterm birth. ${ }^{7}$

The possibility that magnesium sulfate administered to mothers delivering prematurely might prevent cerebral palsy in their infants was first shown in a case-control study ${ }^{8}$ in which children with cerebral palsy were much less likely to have been exposed to magnesium sulfate than were control subjects (odds ratio, $0.14 ; 95 \%$ confidence interval [CI], 0.05 to 0.51 ). This protective association has biologic plausibility, because magnesium may reduce vascular instability, prevent hypoxic damage, and mitigate cytokine or excitatory amino acid damage, all of which threaten the vulnerable preterm brain. ${ }^{9}$ We performed this study to test the hypothesis that the administration of magnesium sulfate to women at high risk for early preterm delivery would reduce the risk of cerebral palsy in their children.

\section{METHODS \\ RECRUITMENT}

This trial was conducted at 20 participating Eunice Kennedy Shriver National Institute of Child Health and Human Development Maternal-Fetal Medicine Units Network sites across the United States. Women were eligible if they were carrying singletons or twins at 24 through 31 weeks of gestation and were at high risk for spontaneous delivery because of rupture of the membranes occurring at 22 through 31 weeks of gestation or because of advanced preterm labor with dilatation of 4 to $8 \mathrm{~cm}$ and intact membranes. They were also eligible if an indicated preterm delivery was anticipated within 2 to 24 hours (e.g., because of fetal growth restriction). Women were not eligible if delivery was anticipated within less than 2 hours or if cervical dilatation exceeded $8 \mathrm{~cm}$; in such cases, the intervention was assumed to have little chance of achieving an effect. ${ }^{10}$ Additional exclusion criteria included rupture of the membranes before 22 weeks, unwillingness of the obstetrician to intervene for the benefit of the fetus, major fetal anomalies or death, maternal hypertension or preeclampsia, maternal contraindications to magnesium sulfate (e.g., severe pulmonary disorders), and receipt of intravenous magnesium sulfate within the previous 12 hours. The use of tocolytic drugs after randomization was proscribed.

The duration of gestation was determined at entry to the trial according to a previously described algorithm ${ }^{11}$ that uses the date of the last menstrual period (if reliable) and the results of the earliest available ultrasound examination. The study was approved by the institutional review boards of each clinical site and the data coordinating center. All participants gave written informed consent before enrollment. 


\section{PROTOCOL}

Eligible, consenting women were randomly assigned in a double-blind fashion to receive either intravenous magnesium sulfate (a loading dose of $6 \mathrm{~g}$ infused for 20 to 30 minutes, followed by a maintenance infusion of $2 \mathrm{~g}$ per hour) or identical-appearing placebo. If delivery had not occurred after 12 hours and was no longer considered imminent (e.g., if the woman was not having regular uterine contractions), the infusion was discontinued and resumed when delivery was deemed imminent again (e.g., when contractions developed). If at least 6 hours had passed since the discontinuation of the study medication, another loading dose was given. Retreatment was withheld if preeclampsia or eclampsia developed (in which case open-label magnesium sulfate was administered for seizure prophylaxis), if it was thought that a delay in delivery in order to administer retreatment would be detrimental to the mother or the fetus, or if the gestational age had reached 34 weeks. Adherence to the protocol was monitored at each site on an ongoing basis by the data coordinating center.

Group assignment was made according to a computer-generated random sequence, ${ }^{12}$ with stratification according to clinical center and, in twin pregnancies, weeks of gestation $(<28$ or $\geq 28$ ). Certified research nurses collected information on the mother's demographic features, medical history, and social history at enrollment in the study. The nurses also obtained data on neonatal and maternal outcomes at delivery and at scheduled follow-up visits when the infant reached 6, 12, and 24 months of age (corrected for prematurity).

\section{STUDY OUTCOMES}

The primary outcome was the composite of stillbirth or infant death by 1 year of age or moderate or severe cerebral palsy, as assessed at or beyond 2 years of age (with ages corrected for prematurity). Death before 1 year of age was included because it is a competing outcome that would preclude the assessment of cerebral palsy. We considered it possible to make a diagnosis of cerebral palsy at 1 year, although our goal was to make this diagnosis on the basis of the 2year examination. Those infants who had a normal neurologic examination at 1 year, could walk 10 steps independently, and had a bilateral pincer grasp were declared free of cerebral palsy and, for the purpose of the primary outcome, were considered normal. No further neurologic examination was required for these infants, since, by definition, cerebral palsy is nonprogressive. We chose to include only moderate or severe cerebral palsy in the primary outcome because cerebral palsy of this severity at or beyond 2 years of age portends lifelong motor dysfunction, whereas mild cerebral palsy may resolve. ${ }^{13}$

An annually certified pediatrician or pediatric neurologist made a diagnosis of cerebral palsy if two or more of the following three features were present: a delay of $30 \%$ or more in gross motor developmental milestones (e.g., inability to sit without arm support by 9.5 months or walk by 17 months of corrected age)14,15; abnormality in mus cle tone (e.g., scissoring), 4+ or absent deep-tendon reflexes, or movement abnormality (e.g., posturing or gait asymmetry); or persistence of primitive reflexes or absence of protective reflexes.

When cerebral palsy was diagnosed, the Gross Motor Function Classification System $(\text { GMFCS })^{16}$ was used to assess severity. At a corrected age of 2 years or more, a child who was classified as functioning at GMFCS level 2 or above (GMFCS scores can range from 0 to 5 , with higher scores indicating greater impairment; children with scores of 2 or above are unable to walk independently) or who did not have the ability to grasp and release a 1-in. (2.54$\mathrm{cm}$ ) block with both hands was considered to have at least moderately handicapping cerebral palsy. Mild cerebral palsy was defined as a GMFCS grade of level 1, moderate cerebral palsy as a grade of level of 2 or 3 , and severe cerebral palsy as a grade of level 4 or 5 . 
If children were not available within the 24-to-28-month window for the 2-year examination, efforts were made to reschedule their appointments, regardless of their age. For 28 children who were not evaluated at 2 years of age but were not declared free of cerebral palsy at the age of 1 year, two pediatric neurologists who were unaware of the treatment assignment judged whether the children had moderate or severe cerebral palsy on the basis of a review of the 1year examination.

Prespecified secondary outcomes included various maternal outcomes and complications; adverse events potentially attributable to the study intervention; neonatal complications; cerebral palsy at 2 years of age classified as mild, moderate, or severe; stillbirth; infant death; and scores on the Bayley Scales of Infant Development II, ${ }^{17}$ administered at the 2-year examination by a trained psychologist or psychometrist. Cranial ultrasound examinations were performed on all neonates and were read centrally by three independent pediatric radiologists.

We performed nonprespecified analyses that were stratified according to whether randomization occurred before 28 weeks or at 28 or more weeks of gestation, whether the gestation was singleton or twin, and whether the fetus had been previously exposed to magnesium sulfate. We also performed an analysis of the primary outcome and its components, excluding infants who had major congenital anomalies that were discovered after birth. Before this analysis, a single clinical geneticist (without knowledge of study-group assignment) classified anomalies as major or minor on the basis of a review of the medical records according to standard criteria. ${ }^{18}$

\section{STATISTICAL ANALYSIS}

We estimated that the primary outcome would occur in $14 \%$ of the placebo group, on the assumption of a rate of death of $6 \%, 19$ and that the rate of moderate or severe cerebral palsy among survivors would be $8 \% .{ }^{20}$ Thus, an equally divided sample of 2000 was deemed sufficient for the detection of a $30 \%$ reduction in this outcome, with a type I error (two-sided) of 5\% and a power of at least $80 \%$. On the assumption of a $10 \%$ rate of loss to follow-up, we established a target sample size of 2200.

The data from all patients were analyzed according to the group to which they were randomly assigned, regardless of whether they received the study medication. In any given pregnancy, the primary outcome could be credited only once (i.e., cerebral palsy followed by death counted for only one primary outcome). For all analyses of maternal and primary outcomes, including the components of the primary outcome, the unit of analysis was the pregnancy (i.e., a twin pregnancy was credited with an event if it occurred in either twin). Continuous variables were compared with the use of the Wilcoxon rank-sum test, and categorical variables with the chisquare test, Fisher's exact test, or the Mantel-Haenszel chi-square test for trend. The BreslowDay test was used to test for heterogeneity of treatment effects across strata. For all other neonatal outcomes, log-binomial regression was performed. The unit of analysis was the neonate, with generalized estimating equations used to adjust for the clustering of neonates within pregnancies. Analyses were performed with the use of SAS software, version 8.2.

The group sequential method of Lan and DeMets with the modified O'Brien-Fleming spending function was used for adjustment of the significance level in interim analyses. ${ }^{21}$ Four interim analyses were performed; in the final analysis of the primary outcome, two-tailed $\mathrm{P}$ values of less than 0.043 were considered to indicate statistical significance. However, since the adjustment is minimal, we reported $95 \%$ confidence intervals. For all outcomes other than moderate or severe cerebral palsy and death, a nominal $\mathrm{P}$ value of less than 0.05 was considered to indicate statistical significance, and no adjustments were made for multiple comparisons. An independent data and safety monitoring committee monitored the trial and reviewed the interim results. 


\section{RESULTS}

From December 1997 through May 2004, a total of 2241 eligible women were enrolled (Fig. 1). The baseline characteristics of the two groups were similar (Table 1). The primary outcome was assessed for $95.6 \%$ of fetuses. Ninety-five percent of examinations for cerebral palsy were completed by 32 months of corrected age. In three children who did not have an examination at 2 years, moderate or severe cerebral palsy was diagnosed on the basis of the 1-year examination. The baseline characteristics of the women whose fetuses were lost to follow-up did not differ significantly between the two study groups.

Adherence to the assigned intervention was high, and off-protocol use of magnesium sulfate for tocolysis was infrequent (1.4\%) (Fig. 1). The median total dose of the study drug received by women in the magnesium sulfate group was $31.5 \mathrm{~g}$ (interquartile range, 29.0 to 44.6). Six hundred thirty-nine women $(28.5 \%)$ were not eligible for retreatment. Of the 1602 women (71.5\%) who were eligible for retreatment, 947 (59.1\%) were receiving the study drug at delivery. The most common reasons that indicated retreatment did not occur were staff error and urgent cesarean delivery.

The primary composite outcome of moderate or severe cerebral palsy or death occurred in 118 $(11.3 \%)$ of the 1041 pregnancies in which the mothers were assigned to receive magnesium sulfate and $128(11.7 \%)$ of the 1095 pregnancies in which the mothers were assigned to receive placebo (relative risk, $0.97 ; 95 \% \mathrm{CI}, 0.77$ to 1.23 ) (Table 2). The risk of giving birth to an infant subsequently receiving a diagnosis of moderate or severe cerebral palsy was lower among women in the magnesium sulfate group than among women in the placebo group (1.9\% vs. $3.5 \%$; relative risk, $0.55 ; 95 \% \mathrm{CI}, 0.32$ to $0.95 ; \mathrm{P}=0.03$ ), whereas the risk of stillbirth or infant death was slightly higher in the magnesium sulfate group than in the placebo group $(9.5 \%$ vs. $8.5 \%$; relative risk, $1.12 ; 95 \% \mathrm{CI}, 0.85$ to $1.47 ; \mathrm{P}=0.41$ ). Exclusion of children with major congenital anomalies discovered after birth slightly lowered the relative risk of the composite primary outcome and attenuated the relative risk of death but had minimal effect on the relative risk of cerebral palsy (Table 2). Scores on the Bayley scales did not significantly differ between the two groups.

Cerebral palsy was diagnosed in 41 children from 40 of 942 pregnancies in the magnesium sulfate group (4.2\%) and in 74 children from 73 of 1002 pregnancies in the placebo group $(7.3 \%, \mathrm{P}=0.004)$. The percentages of mild, moderate, and severe cerebral palsy (not including diagnoses at 1 year) were $2.2 \%, 1.5 \%$, and $0.5 \%$, respectively, in the magnesium sulfate group and $3.7 \%, 2.0 \%$, and $1.6 \%$, respectively, in the placebo group ( $\mathrm{P}$ for trend $=0.004)$. The results of the stratified analyses, including those of singleton and twin pregnancies, were broadly consistent with those of the primary analysis $(\mathrm{P}>0.05$ for all comparisons with the use of the Breslow-Day test) (Table 3).

Obstetrical outcomes were similar between the groups (Table 4). Adverse events, such as flushing or sweating, were more frequent in the magnesium sulfate group. Discontinuation of study medication was more frequent in the magnesium sulfate group than in the control group ( $4.2 \%$ vs. $1.4 \%, \mathrm{P}<0.001)$. However, there were no life-threatening events or maternal deaths in either group. For a wide variety of neonatal outcomes, no significant differences between the groups were noted (Table 5).

\section{DISCUSSION}

We found that treatment with magnesium sulfate in women at imminent risk for delivery between 24 and 31 weeks of gestation had no significant effect on the primary composite outcome of moderate or severe cerebral palsy or death. Magnesium sulfate was associated with a slight but non-significant increase in the risk of fetal or infant death and a significant decrease 
in the risk of moderate or severe cerebral palsy among surviving children. The exclusion of infants with major congenital malformations discovered after birth attenuated the increase in the risk of death.

Two previous randomized, placebo-controlled trials of antenatal magnesium sulfate for fetal neuroprotection are noteworthy. Crowther et al.22 studied 1062 women at imminent risk for delivery before 30 weeks of gestation. Stillbirth or death of their infants before the age of 2 years was less frequent, albeit not significantly so, among women assigned to receive magnesium sulfate than among those assigned to receive placebo (13.8\% vs. $17.1 \%$; relative risk, $0.83 ; 95 \%$ CI, 0.64 to 1.09 ). Substantial gross motor dysfunction (diagnosed according to criteria essentially identical to our criteria for moderate or severe cerebral palsy) was significantly less frequent among surviving children in the magnesium sulfate group (3.4\% vs. $6.6 \%$; relative risk, $0.51 ; 95 \% \mathrm{CI}, 0.29$ to 0.91 ). Marret et al. ${ }^{23}$ recently reported 2 -year outcomes of a trial that involved 573 mothers. Infants of women assigned to receive magnesium sulfate had nonsignificantly lower rates of death $(9.7 \%$ vs. $11.3 \%$; relative risk, $0.85 ; 95 \% \mathrm{CI}$, 0.55 to 1.32$)$ and of cerebral palsy among survivors ( $7.0 \%$ vs. $10.2 \%$; relative risk, $0.69 ; 95 \%$ CI, 0.41 to 1.16$)$.

Preterm labor with intact membranes was the predominant indication for enrollment in those two trials. In our study, such a diagnosis was often considered an indication for tocolysis by the managing clinicians, and thus preterm premature rupture of membranes predominated.

In both the trial by Crowther et al..$^{22}$ and the present trial, the $95 \%$ confidence interval around the reduced relative risk of moderate or severe cerebral palsy (what Crowther et al. refer to as "substantial gross motor dysfunction") does not include 1; however, because this outcome alone is viewed as a secondary outcome, the result is not statistically compelling.

Other randomized trials of magnesium sulfate administered to mothers for fetal neuroprotection have been much less informative. One small study of 150 women was conducted as a feasibility trial and did not report follow-up rates ${ }^{24,25}$; its methodologic limitations have been previously detailed. ${ }^{26-30}$ Another trial was not primarily designed to address the question of fetal neuroprotection, and the follow-up rate was low. ${ }^{31}$

Neither the present trial nor the trials of Crowther et al. or Marret et al. demonstrated a statistically significant effect of magnesium sulfate on the composite outcome of death or cerebral palsy. Although composite outcomes have their shortcomings, ${ }^{32}$ in a trial of this nature they are essential, since, as Crowther et al. noted, ${ }^{33}$ "a child cannot have motor dysfunction at 2 years if he or she has already died." An additional reason to include death in the composite outcome is that the small study by Mittendorf et al. ${ }^{24}$ suggested that magnesium sulfate significantly increased mortality; this finding was aggressively promoted, ${ }^{25}$ even though we and others disputed it. ${ }^{26-30}$

Infants who are at high risk for prematurity-associated cerebral palsy are at even greater risk for death. In our trial, death was three to four times as common as moderate or severe cerebral palsy; this end point dominates the combined end point. Thus, even when the rate of death does not differ significantly between groups (as in the three most pertinent trials), the potential for a difference in the rates of cerebral palsy to result in a significant difference in the rate of the composite outcome is small unless the sample is very large. We anticipated a higher rate of moderate or severe cerebral palsy in planning the trial than we actually observed, and this limited our statistical power to detect a difference in the composite outcome. We speculate that our rigorous diagnostic criteria accounted for this lower rate.

Overall, our study showed no significant effect of magnesium sulfate on the combined end point of death or moderate or severe cerebral palsy. However, consistent with the results of 
previous trials, our findings suggest that magnesium sulfate may reduce the chance that cerebral palsy will subsequently be diagnosed in a child who was at high risk for preterm birth.

\title{
Acknowledgments
}

Supported by grants from the NICHD and the National Institute of Neurological Disorders and Stroke (HD27869, HD34208, HD34116, HD40544, HD27915, HD34136, HD21414, HD27917, HD27860, HD40560, HD40545, HD40485, HD40500, HD27905, HD27861, HD34122, HD40512, HD53907, HD34210, HD21410, HD36801, and HD19897).

\begin{abstract}
We thank Steven Weiner, M.S., for protocol and data management and statistical analysis; Allison Northen, R.N., for coordination between clinical research centers; Karin Nelson, M.D., for study design and protocol development; Kenneth J. Leveno, M.D., for protocol development and oversight; Peter Blasco, M.D., for development of the pediatric neurology definitions, training of study examiners, and outcome review; John Hauth, M.D., and Donald McNellis, M.D., for initial study design and for protocol development and support; Bruce Shapiro, M.D., for training and certification of study examiners; Robert Palisano, M.D., for assistance with the Gross Motor Function Classification System; Michael DiPietro, M.D., Dorothy Bulas, M.D., and Joanna Siebert, M.D., for central review of cranial ultrasonograms; Theresa Leach, M.S., for quality assurance monitoring of the Bayley examinations; Susan McCune, M.D., for central review of outcomes; Joseph R. Biggio, M.D., for classification of congenital anomalies; and Jeffrey S.A. Stringer, M.D., for review of the manuscript.
\end{abstract}

\section{APPENDIX}

The other members of the Eunice Kennedy Shriver National Institute of Child Health and Human Development (NICHD) Maternal-Fetal Medicine Units Network are as follows: University of Alabama at Birmingham, Birmingham: J. Hauth, A. Northen; follow-up - K.G. Nelson, M. Peralta-Carcelen, T. Hill-Webb, S. Tate, C. Lee, K. Bailey, S. Chopko, R. Rector, F.J. Biasini. University of Utah, Salt Lake City: K. Anderson, A. Guzman, M. Jensen; followup - A. Bodnar, L. Adams, L. Fullmer, M. Thompson, L. Williams, M. Steffen, A. Miller. University of Texas Southwestern Medical Center, Dallas: K. Leveno, M.L. Sherman, J. Dax, L. Faye-Randall, C. Melton; follow-up - R. Heyne, P. Hicks, R.S. Broyles, E. Flores, P. Orduno, B. Cordova, C. Dooley, C. Boatman. Case Western Reserve University, Cleveland: G. VanBuren, C. Milluzzi, C. Santori; follow-up - M. Collin, M. Fundzak, B. Nielsen. Ohio State University, Columbus: F. Johnson, M.B. Landon, C. Latimer, V. Curry, S. Meadows; follow-up - L. Cordero, C. Timan, P. Giannone, S. Brenner, R. Selegue. Thomas Jefferson University, Philadelphia: A. Sciscione, M.M. DiVito; follow-up - S. Desai, K. Esterly, C. Duran, D. Paul, A. Herman, P. DiVito, M. Sherman, A. O'shea, M. Talucci, M. Gringlas, A.M. Higley, E. Gaines, N. Colley, E.A. Higley. University of Tennessee, Memphis: B.M. Sibai, R. Ramsey, B. Mabie, L. Kao, M. Cassie; follow-up - M. Petersen, A. Talati, T. Whitaker, H. Bada, J. McKeever, S. Werkman, J. Rowland, L. Pollard. Wayne State University, Detroit: G.S. Norman, B. Steffy, M.P. Dombrowski; follow-up - V. Delaney-Black, Y. Johnson, D. Driscoll, L. Goldston, K. Boyes. Wake Forest University, Winston-Salem, NC: P. Meis, M. Swain; follow-up - K. Klinepeter, M. O'shea, C. Heller, L. Steele, M. Kiger, J. Kreeger, E. Waldrep, K. Rhodes, D. Allred, R. Halfond, G. Hounshell, N. Hall, L. Barr. University of North Carolina, Chapel Hill: K.J. Moise, Jr., S. Brody, K. Dorman; follow-up - K. Milowic, D. Marshall, J. Bernhardt, L. Bostic. University of Texas at Houston, Houston: L.C. Gilstrap III, M.C. Day, E. Gildersleeve, F. Ortiz, M. Kerr; follow-up - B.H. Morris, M. Chavarria, P. Bradt, S. Legé-Humbert, S. Dieterich. Columbia University, New York: V. Pemberton, S. Bousleiman; follow-up - C. Paley, J. Lee, L. Paley, V. Carmona. Brown University, Providence, RI: J. Tillinghast, D. Allard, K. McCarten; follow-up - B. Vohr, L. Noel, C. Mejia, V. Watson, M. Leonard, T. Leach. University of Cincinnati, Cincinnati: N. Elder, W. Girdler; follow-up - J. Steichen, T. Gratton. University of Chicago, Chicago: M. Lindheimer, P. Jones; follow-up - N. Roizen, L. Gray, C. Wicks, A. Rossi, S. Plesha-Troyke. University of Miami, Miami: F. Doyle, C. Alfonso, M. Scott, R. Washington; follow-up - S. FajardoHiriart, A. Londono, G. Rocha-Rodriguez, A. Worth, W. Griffin, M. Allison, A. Diaz, S. FradeEguaras. Northwestern University, Chicago: G. Mallett, P. Simon; follow-up - R. deRegnier, 
M. de Ungria, K. Mestan, M. Ramos-Brinson, L. Bethel, M. Weissbourd, M. Shivers. University of Texas Medical Branch, Galveston: L.A. Goodrum, G.R. Saade, M. Munn, J. Moss, J. Brandon, G.L. Olson, H.M. Harirah, E. Martin; follow-up - D. Dallas, T. Santiago, B. Stratton, E. Shipley, K. Smith. University of Texas at San Antonio, San Antonio: E. Xenakis, D. Conway, M. Berkus; follow-up - R. Castro, M. Odom, D. Skiver, N. Ramirez, E. Miller, C. McLerran, K. Matula-Linkhart. University of Pittsburgh, Pittsburgh: M. Cotroneo, C. Milford; follow-up - D. Hofkosh, T. Kamon, C. Milford. George Washington University Biostatistics Center, Washington, DC: S. Weiner, B. Jones-Binns, M. Hoover, M. Fischer, S. McLaughlin, K. Brunette, E. Fricks. NICHD, Bethesda, MD: S. Pagliaro, D. McNellis, C. Katz, K. Howell.

\section{References}

1. Executive Committee for the Definition of Cerebral Palsy. Proposed definition and classification of cerebral palsy, April 2005. Dev Med Child Neurol 2005;47:571-6. [PubMed: 16108461]

2. Kuban KCK, Leviton A. Cerebral palsy. N Engl J Med 1994;330:188-95. [PubMed: 8264743]

3. Cummins SK, Nelson KB, Grether JK, Veile EM. Cerebral palsy in four northern California counties, births 1983 through 1985. J Pediatr 1993;123:230-7. [PubMed: 8345418]

4. Robertson CMT, Watt M-J, Yasui Y. Changes in the prevalence of cerebral palsy for children born very prematurely in a population-based program over 30 years. JAMA 2007;297:2733-40. [PubMed: 17595274]

5. Tommiska V, Heinonen K, Lehtonen L, et al. No improvement in outcome of nationwide extremely low birthweight infant populations between 1996-1997 and 1999-2000. Pediatrics 2007;119:29-36. [PubMed: 17200268]

6. Vincer MJ, Allen AC, Joseph KS, Stinson DA, Scott H, Wood E. Increasing prevalence of cerebral palsy among very preterm infants: a population-based study. Pediatrics 2006;118(6):e1621-e1626. [PubMed: 17074842]

7. Winter S, Autry A, Boyle C, Yeargin-Allsopp M. Trends in the prevalence of cerebral palsy in a population-based study. Pediatrics 2002;110:1220-5. [PubMed: 12456922]

8. Nelson KB, Grether JK. Can magnesium sulfate reduce the risk of cerebral palsy in very low birthweight infants? Pediatrics 1995;95:263-9. [PubMed: 7838646]

9. Hirtz DG, Nelson KN. Magnesium sulfate and cerebral palsy in premature infants. Curr Opin Pediatr 1998;10:131-7. [PubMed: 9608889]

10. Hallak M, Berry SM, Madincea F, Romero R, Evans MI, Cotton DB. Fetal serum and amniotic fluid magnesium concentrations with maternal treatment. Obstet Gynecol 1993;81:185-8. [PubMed: 8423946]

11. Carey JC, Klebanoff MA, Hauth JC, et al. Metronidazole to prevent preterm delivery in pregnant women with asymptomatic bacterial vaginosis. N Engl J Med 2000;342:534-40. [PubMed: 10684911]

12. Wei LJ, Lachin JM. Properties of the urn randomization in clinical trials. Control Clin Trials 1988;9:345-64. [PubMed: 3203525] [Erratum, Control Clin Trials 1989;10:following 126.]

13. Nelson KB, Ellenberg JH. Children who "outgrew” cerebral palsy. Pediatrics 1982;69:529-36. [PubMed: 7079007]

14. Capute AJ, Shapiro BK. The motor quotient: a method for the early detection of motor delay. Am J Dis Child 1985;139:940-2. [PubMed: 4036929]

15. Blasco PA. Primitive reflexes: their contribution to the early detection of cerebral palsy. Clin Pediatr (Phila) 1994;33:388-97. [PubMed: 7955781]

16. Palisano R, Rosenbaum P, Walter S, Russell D, Wood E, Galuppi B. Development and reliability of a system to classify gross motor function in children with cerebral palsy. Dev Med Child Neurol 1997;39:214-23. [PubMed: 9183258]

17. Bayley, N. Bayley scales of infant development. Vol. 2nd ed.. Psychological Corporation; New York: 1993. 
18. Stevenson, RE.; Hall, JG. Terminology.. In: Stevenson, RE.; Hall, JD.; Goodman, RM., editors. Human malformations and related anomalies. Oxford University Press; Oxford, England: 1993. p. 21-30.

19. Mercer BM, Miodovnik M, Thurnau GR, et al. Antibiotic therapy for reduction of infant morbidity after preterm premature rupture of the membranes: a randomized controlled trial. JAMA 1997;278:989-95. [PubMed: 9307346]

20. Pinto-Martin JA, Riolo S, Cnaan A, Holzman C, Susser MW, Paneth N. Cranial ultrasound prediction of disabling and nondisabling cerebral palsy at age two in a low birth weight population. Pediatrics 1995;95:249-54. [PubMed: 7838643] [Erratum, Pediatrics 2001; 108:238.]

21. Lan KKG, DeMets DL. Discrete sequential boundaries for clinical trials. Biometrika 1983;70:659_ 63.

22. Crowther CA, Hiller JE, Doyle LW, Haslam RR. Effect of magnesium sulfate given for neuroprotection before preterm birth: a randomized controlled trial. JAMA 2003;290:2669-76. [PubMed: 14645308]

23. Marret S, Marpeau L, Follet-Bouhamed C, et al. Effect of magnesium sulphate on mortality and neurologic morbidity of the very-preterm newborn (of less than 33 weeks) with two-year neurological outcome: results of the prospective PREMAG trial. Gynecol Obstet Fertil 2008;36:278-88. (In French.). [PubMed: 18337147]

24. Mittendorf R, Covert R, Boman J, Khoshnood B, Lee KS, Siegler M. Is tocolytic magnesium sulphate associated with increased total paediatric mortality? Lancet 1997;350:1517-8. [PubMed: 9388401]

25. Mittendorf R, Dambrosia J, Pryde PG, et al. Association between the use of antenatal magnesium sulfate in preterm labor and adverse health outcomes in infants. Am J Obstet Gynecol 2002;186:1111-8. [PubMed: 12066082]

26. Grether J, Hirtz D, McNellis D, Nelson K, Rouse DJ. Tocolytic magnesium sulphate and paediatric mortality. Lancet 1998;351:292. [PubMed: 9457123]

27. Rouse DJ, Hirtz DG, Thom E. Association between use of antenatal magnesium sulfate in preterm labor and adverse health outcomes in infants. Am J Obstet Gynecol 2003;188:295. [PubMed: 12548234]

28. Crowther C, Hiller J, Doyle L, Lumley J, Carlin J. Tocolytic magnesium sulphate and paediatric mortality. Lancet 1998;351:291. [PubMed: 9457121]

29. Leveno KJ. Tocolytic magnesium sulphate and paediatric mortality. Lancet 1998;351:291-2. [PubMed: 9457122]

30. Bénichou J, Zupan V, Fernandez H, Marpeau L, Marret S. Tocolytic magnesium sulphate and paediatric mortality. Lancet 1998;351:290-1. [PubMed: 9457120]

31. Magpie Trial Follow-Up Study Collaborative Group. The Magpie Trial: a randomized trial comparing magnesium sulphate with placebo for pre-eclampsia: outcome for children at 18 months. BJOG 2007;114:289-99. [PubMed: 17166221]

32. Montori VM, Permanyear-Miralda G, Ferreira-González I, et al. Validity of composite end points in clinical trials. BMJ 2005;330:594-6. [PubMed: 15761002]

33. Crowther CA, Hiller JE, Doyle LW, Haslam RR. Magnesium sulfate for preterm neuroprotection. JAMA 2004;291:941. [PubMed: 14982908] 


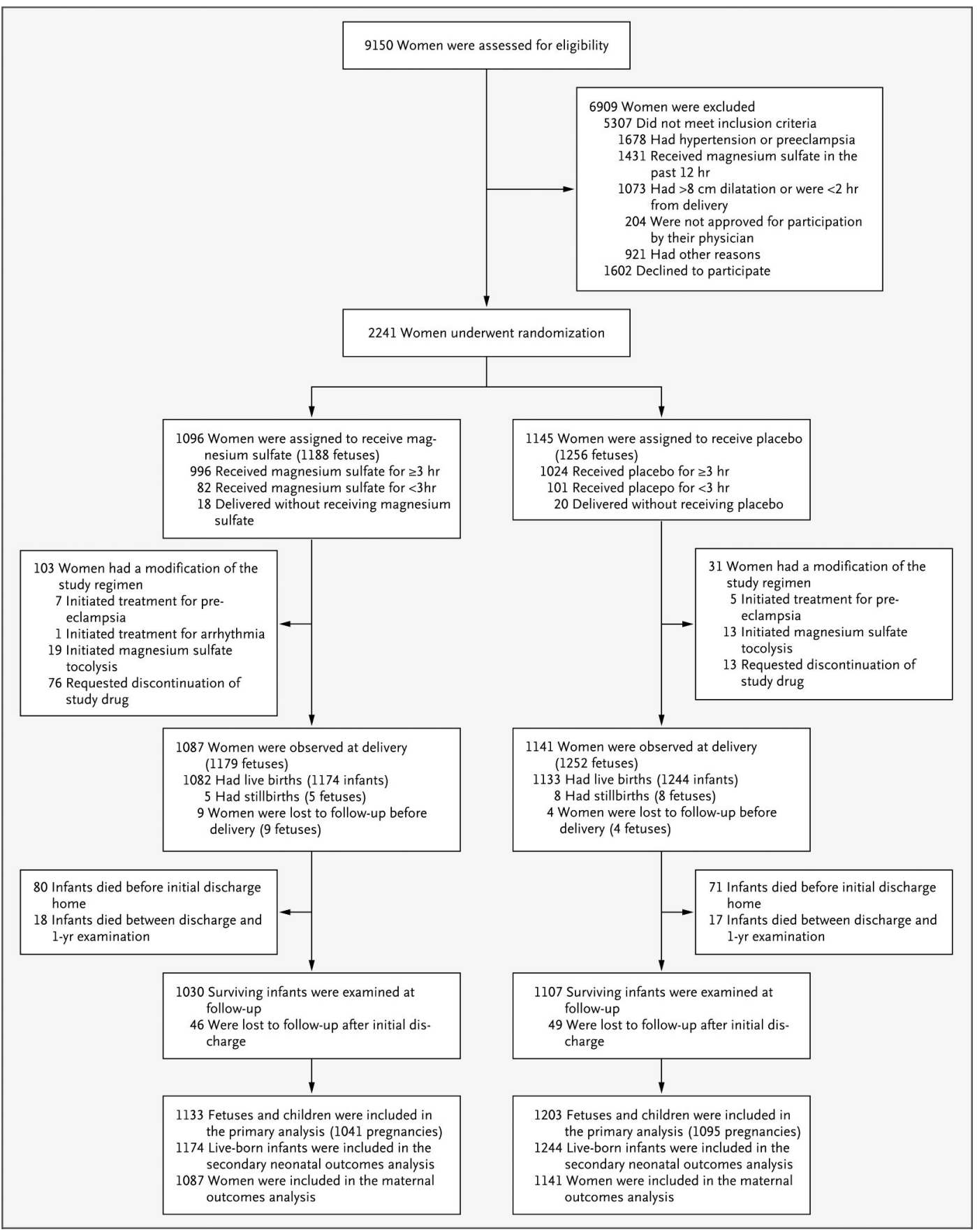

Figure 1.

Enrollment, Randomization, and Follow-up of the Study Participants. 


\section{Table 1}

\section{Baseline Characteristics of the Mothers.*}

\begin{tabular}{|c|c|c|}
\hline Characteristic & Magnesium Sulfate ( $N=1096$ ) & Placebo $(N=1145)$ \\
\hline Weeks of gestation at randomization & $28.3 \pm 2.5$ & $28.2 \pm 2.4$ \\
\hline Maternal age $-\mathrm{yr}$ & $26.1 \pm 6.3$ & $25.9 \pm 6.2$ \\
\hline Maternal prepregnancy body-mass index ${ }^{\dagger}$ & $26.0 \pm 6.7$ & $26.4 \pm 6.9$ \\
\hline \multicolumn{3}{|l|}{ Maternal race or ethnic group - no. $(\%)^{\%}$} \\
\hline Black & $483(44.1)$ & $495(43.2)$ \\
\hline White & $404(36.9)$ & $418(36.5)$ \\
\hline Hispanic & $184(16.8)$ & $206(18.0)$ \\
\hline Other & $25(2.3)$ & $26(2.3)$ \\
\hline Married — no./total no. (\%) & $549 / 1094(50.2)$ & $530 / 1142(46.4)$ \\
\hline Educational level - yr & $11.8 \pm 2.5$ & $11.8 \pm 2.5$ \\
\hline Nulliparous — no. (\%) & $391(35.7)$ & $414(36.2)$ \\
\hline Previous preterm delivery — no. $(\%)$ & $292(26.6)$ & $310(27.1)$ \\
\hline No prenatal care - no. $(\%)$ & $78(7.1)$ & $88(7.7)$ \\
\hline Smoking during pregnancy - no. $(\%)$ & $299(27.3)$ & $319(27.9)$ \\
\hline Alcohol use during pregnancy - no. $(\%)$ & $93(8.5)$ & $96(8.4)$ \\
\hline Illicit-substance use during pregnancy - no. $(\%)$ & $108(9.9)$ & $104(9.1)$ \\
\hline Twin gestation — no. (\%) & $92(8.4)$ & $111(9.7)$ \\
\hline Magnesium sulfate before enrollment - no. $(\%)$ & $201(18.3)$ & $218(19.0)$ \\
\hline \multicolumn{3}{|l|}{ Qualifying eligibility criterion } \\
\hline Premature rupture of membranes - no. $(\%)$ & $947(86.4)$ & $995(86.9)$ \\
\hline \multicolumn{3}{|l|}{ Time since rupture $-\mathrm{hr} \S$} \\
\hline Median & 25.2 & 24.4 \\
\hline Interquartile range & $10.7-61.1$ & $10.8-62.9$ \\
\hline Advanced preterm labor — no. $(\%)$ & $116(10.6)$ & $114(10.0)$ \\
\hline Cervical dilatation $-\mathrm{cm}$ & $4.8 \pm 1.2$ & $4.6 \pm 1.0$ \\
\hline Indicated preterm delivery — no. $(\%)$ & $33(3.0)$ & $36(3.1)$ \\
\hline
\end{tabular}

Plus-minus values are means $\pm \mathrm{SD}$. P $>0.05$ for all between-group comparisons

The body-mass index is the weight in kilograms divided by the square of the height in meters. Values were unavailable for 111 mothers in the magnesium sulfate group and 128 in the placebo group.

${ }^{*}$ Race or ethnic group was self-reported. Percentages may not total 100 because of rounding.

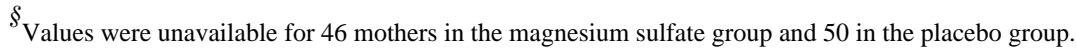


Table 2

Outcomes Assessed at Follow-up.

\begin{tabular}{|c|c|c|c|c|}
\hline Outcome & $\begin{array}{c}\text { Magnesium } \\
\text { Sulfate }(\mathrm{N}=1041)\end{array}$ & Placebo $(N=1095)$ & $\begin{array}{l}\text { Relative Risk } \\
\text { (95\% CI) }\end{array}$ & P Value \\
\hline \multicolumn{5}{|c|}{ no./total no. (\%) } \\
\hline All pregnancies & & & & \\
\hline $\begin{array}{l}\text { Moderate or severe } \\
\text { cerebral palsy or death }\end{array}$ & $118 / 1041(11.3)$ & $128 / 1095(11.7)$ & $0.97(0.77-1.23)$ & 0.80 \\
\hline $\begin{array}{l}\text { Moderate or severe } \\
\text { cerebral palsy alone }\end{array}$ & 20/1041 (1.9) & $38 / 1095(3.5)$ & $0.55(0.32-0.95)$ & 0.03 \\
\hline Death alone & $99 / 1041(9.5)$ & $93 / 1095(8.5)$ & $1.12(0.85-1.47)$ & 0.41 \\
\hline \multicolumn{5}{|l|}{$\begin{array}{l}\text { Pregnancies without } \\
\text { major congenital } \\
\text { anomalies }\end{array}$} \\
\hline $\begin{array}{l}\text { Moderate or severe } \\
\text { cerebral palsy or death* }\end{array}$ & 100/997 (10.0) & $117 / 1063(11.0)$ & $0.91(0.71-1.17)$ & 0.47 \\
\hline $\begin{array}{l}\text { Moderate or severe } \\
\text { cerebral palsy alone }\end{array}$ & 18/997 (1.8) & $34 / 1063(3.2)$ & $0.56(0.32-0.99)$ & 0.04 \\
\hline Death alone & $83 / 997$ (8.3) & $86 / 1063(8.1)$ & $1.03(0.77-1.37)$ & 0.85 \\
\hline \multicolumn{5}{|l|}{$\begin{array}{l}\text { Scores on the Bayley } \\
\text { Scales of Infant } \\
\text { Development }\end{array}$} \\
\hline $\begin{array}{c}\text { Psychomotor } \\
\text { Development Index }<70\end{array}$ & $134 / 876(15.3)$ & $144 / 919(15.7)$ & $0.98(0.79-1.21)$ & 0.83 \\
\hline $\begin{array}{c}\text { Psychomotor } \\
\text { Development Index }<85\end{array}$ & $299 / 876(34.1)$ & $315 / 919(34.3)$ & $1.00(0.88-1.13)$ & 0.95 \\
\hline $\begin{array}{l}\text { Mental Development } \\
\text { Index }<70\end{array}$ & $165 / 876(18.8)$ & $171 / 919(18.6)$ & $1.01(0.83-1.23)$ & 0.90 \\
\hline $\begin{array}{l}\text { Mental Development } \\
\text { Index }<85\end{array}$ & $406 / 876(46.3)$ & $427 / 919(46.5)$ & $1.00(0.90-1.10)$ & 0.96 \\
\hline
\end{tabular}

In one twin pregnancy in the magnesium sulfate group and in three twin pregnancies in the placebo group, one of the fetuses was stillborn or died as an infant, whereas the other survived and subsequently received a diagnosis of moderate or severe cerebral palsy. Thus, the number of pregnancies associated with death alone and the number of pregnancies associated with moderate or severe cerebral palsy alone do not add up to the number of pregnancies associated with moderate or severe cerebral palsy or death. 
Table 3

Stratified Analyses of the Primary Outcome and Its Components. ${ }^{*}$

\begin{tabular}{|c|c|c|c|}
\hline Outcome & $\begin{array}{r}\text { Magnesium Sulfate }(\mathrm{N}=1041) \\
\text { no./total no. }\end{array}$ & Placebo $(\mathrm{N}=1095)$ & $\begin{array}{l}\text { Relative Risk (95\% } \\
\text { CI) }\end{array}$ \\
\hline \multicolumn{4}{|c|}{ Primary outcome } \\
\hline \multicolumn{4}{|c|}{$\begin{array}{l}\text { Weeks of gestation at } \\
\text { randomization }\end{array}$} \\
\hline$<28$ & $89 / 442(20.1)$ & $105 / 496(21.2)$ & $0.95(0.74-1.22)$ \\
\hline$\geq 28$ & 29/599 (4.8) & $23 / 599(3.8)$ & $1.26(0.74-2.15)$ \\
\hline \multicolumn{4}{|c|}{$\begin{array}{l}\text { Magnesium sulfate } \\
\text { treatment before } \\
\text { randomization }\end{array}$} \\
\hline Yes & 27/192 (14.1) & 26/210 (12.4) & $1.14(0.69-1.88)$ \\
\hline No & $91 / 849(10.7)$ & 102/885 (11.5) & $0.93(0.71-1.21)$ \\
\hline \multicolumn{4}{|c|}{$\begin{array}{l}\text { Singleton or twin } \\
\text { pregnancy }\end{array}$} \\
\hline Singleton & $97 / 950(10.2)$ & 103/985 (10.5) & $0.98(0.75-1.27)$ \\
\hline Twin & 21/91 (23.1) & $25 / 110(22.7)$ & $1.02(0.61-1.69)$ \\
\hline \multicolumn{4}{|c|}{$\begin{array}{l}\text { Moderate or severe } \\
\text { cerebral palsy }\end{array}$} \\
\hline \multicolumn{4}{|c|}{$\begin{array}{l}\text { Weeks of gestation at } \\
\text { randomization }\end{array}$} \\
\hline$<28$ & $12 / 442(2.7)$ & $30 / 496(6.0)$ & $0.45(0.23-0.87)$ \\
\hline$\geq 28$ & $8 / 599(1.3)$ & $8 / 599(1.3)$ & $1.00(0.38-2.65)$ \\
\hline \multicolumn{4}{|c|}{$\begin{array}{l}\text { Magnesium sulfate } \\
\text { treatment before } \\
\text { randomization }\end{array}$} \\
\hline Yes & $6 / 192(3.1)$ & $11 / 210(5.2)$ & $0.60(0.23-1.58)$ \\
\hline No & $14 / 849(1.6)$ & $27 / 885(3.1)$ & $0.54(0.29-1.02)$ \\
\hline \multicolumn{4}{|c|}{$\begin{array}{l}\text { Singleton or twin } \\
\text { pregnancy }\end{array}$} \\
\hline Singleton & $14 / 950(1.5)$ & 28/985 (2.8) & $0.52(0.27-0.98)$ \\
\hline Twin & 6/91 (6.6) & $10 / 110(9.1)$ & $0.73(0.27-1.92)$ \\
\hline \multicolumn{4}{|c|}{ Fetal or infant death } \\
\hline \multicolumn{4}{|c|}{$\begin{array}{l}\text { Weeks of gestation at } \\
\text { randomization }\end{array}$} \\
\hline$<28$ & 78/442 (17.6) & 78/496 (15.7) & $1.12(0.84-1.49)$ \\
\hline$\geq 28$ & $21 / 599(3.5)$ & $15 / 599(2.5)$ & $1.40(0.73-2.69)$ \\
\hline \multicolumn{4}{|c|}{$\begin{array}{l}\text { Magnesium sulfate } \\
\text { treatment before } \\
\text { randomization }\end{array}$} \\
\hline Yes & 21/192 (10.9) & $15 / 210(7.1)$ & $1.53(0.81-2.88)$ \\
\hline No & 78/849 (9.2) & 78/885 (8.8) & $1.04(0.77-1.41)$ \\
\hline \multicolumn{4}{|c|}{$\begin{array}{l}\text { Singleton or twin } \\
\text { pregnancy }\end{array}$} \\
\hline Singleton & $83 / 950(8.7)$ & 75/985 (7.6) & $1.15(0.85-1.55)$ \\
\hline Twin & 16/91 (17.6) & $18 / 110(16.4)$ & $1.07(0.58-1.98)$ \\
\hline
\end{tabular}

N Engl J Med. Author manuscript; available in PMC 2010 January 7. 
The primary outcome was the composite of stillbirth or infant death by 1 year of corrected age or moderate or severe cerebral palsy at or beyond 2 years of corrected age. $\mathrm{P}>0.05$ for all comparisons (Breslow-Day test). 
Table 4

Maternal Obstetrical Outcomes and Adverse Events Potentially Attributable to the Study Intervention.*

\begin{tabular}{|c|c|c|c|}
\hline Variable & $\underset{1096)}{\operatorname{Magnesium~Sulfate}(\mathrm{N}=}$ & Placebo $(N=1145)$ & P Value \\
\hline \multicolumn{4}{|l|}{ Obstetrical outcomes } \\
\hline Gestational age at delivery — wk & $29.8 \pm 3.1$ & $29.7 \pm 3.1$ & 0.32 \\
\hline $\begin{array}{l}\text { Receipt of antenatal corticosteroids - } \\
\text { no. }(\%)\end{array}$ & $1062(96.9)$ & $1116(97.5)$ & 0.49 \\
\hline Chorioamnionitis — no./total no. (\%) & $127 / 1086(11.7)$ & $131 / 1141(11.5)$ & 0.88 \\
\hline Cesarean delivery — no./total no. (\%) & $417 / 1086(38.4)$ & 448/1141 (39.3) & 0.68 \\
\hline Endometritis - no./total no. (\%) & $74 / 1086(6.8)$ & $80 / 1141(7.0)$ & 0.85 \\
\hline Pulmonary edema - no./total no. (\%) & $8 / 1086(0.7)$ & $3 / 1141(0.3)$ & 0.11 \\
\hline \multicolumn{4}{|l|}{ Adverse events ${ }^{\dagger}$} \\
\hline Any adverse event - no./total no. (\%) & $833 / 1078(77.3)$ & $140 / 1125(12.4)$ & $<0.001$ \\
\hline Flushing — no./total no. (\%) & $703 / 1078(65.2)$ & $74 / 1125(6.6)$ & $<0.001$ \\
\hline Sweating - no./total no. $(\%)$ & $307 / 1078(28.5)$ & $28 / 1125(2.5)$ & $<0.001$ \\
\hline $\begin{array}{l}\text { Pain or burning at intravenous site - } \\
\text { no./total no. }(\%)\end{array}$ & $259 / 1078(24.0)$ & $29 / 1125(2.6)$ & $<0.001$ \\
\hline Nausea or vomiting — no./total no. (\%) & $166 / 1078(15.4)$ & $19 / 1125(1.7)$ & $<0.001$ \\
\hline $\begin{array}{l}\text { Respiratory depression — no./total no. } \\
(\%)^{\ddagger}\end{array}$ & $7 / 1078(0.6)$ & $3 / 1125(0.3)$ & 0.22 \\
\hline $\begin{array}{l}\text { Infusion stopped because of adverse } \\
\text { event }- \text { no./total no. (\%) }\end{array}$ & $45 / 1078(4.2)$ & $16 / 1125(1.4)$ & $<0.001$ \\
\hline
\end{tabular}

Plus-minus values are means \pm SD. Except for gestational age, which was established systematically by algorithm, data on outcomes are based on clinical diagnoses in the medical records, and data on adverse events are based on notations in the medical records or direct report by the participant to a research nurse.

${ }^{\dagger}$ Adverse events are reported only for the mothers who received study medication.

*All cases either were self-limited or responded to diuresis and supplemental oxygen. 
Table 5

Selected Neonatal Outcomes According to Treatment Group.*

\begin{tabular}{|c|c|c|c|}
\hline Outcome & $\begin{array}{c}\text { Magnesium } \\
\text { Sulfate }(\mathrm{N}=1174)\end{array}$ & $\begin{array}{l}\operatorname{Placebo}(N= \\
1244)\end{array}$ & $\begin{array}{l}\text { Relative Risk } \\
\quad(95 \% \text { CI })\end{array}$ \\
\hline Birth weight $-\mathrm{g}$ & $1410 \pm 567$ & $1424 \pm 577$ & \\
\hline $\begin{array}{l}\text { 5-Minute Apgar score }<7-\text { no./total no. } \\
(\%)\end{array}$ & 212/1171 (18.1) & $229 / 1240(18.5)$ & $0.96(0.81-1.15)$ \\
\hline $\begin{array}{l}\text { Resuscitation in the delivery room }- \\
\text { no./total no. }(\%)^{\dagger}\end{array}$ & & & $0.92(0.83-1.02)$ \\
\hline None & $194 / 1172(16.6)$ & $197 / 1244(15.8)$ & \\
\hline Oxygen bag, mask, or both & $524 / 1172(44.7)$ & $520 / 1244(41.8)$ & \\
\hline Intubation & $412 / 1172(35.2)$ & $487 / 1244(39.1)$ & \\
\hline Chest compressions & $42 / 1172(3.6)$ & $40 / 1244(3.2)$ & \\
\hline $\begin{array}{l}\text { Hypotension treated with vasopressors } \\
\text { - no./total no. }(\%)\end{array}$ & $248 / 1171(21.2)$ & $265 / 1244(21.3)$ & $1.00(0.85-1.17)$ \\
\hline $\begin{array}{l}\text { Generalized hypotonicity — no./total no. } \\
(\%)\end{array}$ & $85 / 1171(7.3)$ & $88 / 1244(7.1)$ & $1.00(0.75-1.35)$ \\
\hline $\begin{array}{l}\text { Culture-proven sepsis - no./total no. } \\
(\%)\end{array}$ & $200 / 1171(17.1)$ & $220 / 1244(17.7)$ & $0.97(0.81-1.16)$ \\
\hline $\begin{array}{l}\text { Necrotizing enterocolitis }- \text { no./total no. } \\
(\%)\end{array}$ & $116 / 1171(9.9)$ & $94 / 1244(7.6)$ & $1.27(0.97-1.66)$ \\
\hline $\begin{array}{l}\text { Retinopathy of prematurity }- \text { no./total } \\
\text { no. }(\%)\end{array}$ & $263 / 1171(22.5)$ & 283/1244 (22.7) & $0.98(0.84-1.15)$ \\
\hline $\begin{array}{l}\text { Respiratory distress syndrome }- \text { no./ } \\
\text { total no. }(\%)\end{array}$ & $585 / 1171(50.0)$ & $656 / 1244(52.7)$ & $0.96(0.88-1.04)$ \\
\hline $\begin{array}{l}\text { Mechanical ventilation }- \text { no./total no. } \\
(\%)\end{array}$ & $613 / 1171(52.3)$ & 709/1244 (57.0) & $0.92(0.85-0.99)$ \\
\hline $\begin{array}{l}\text { Bronchopulmonary dysplasia - no./ } \\
\text { total no. }(\%)\end{array}$ & 213/1171 (18.2) & $218 / 1244(17.5)$ & $1.03(0.86-1.23)$ \\
\hline $\begin{array}{l}\text { Patent ductus arteriosus - no./total no. } \\
(\%)\end{array}$ & $151 / 1171(12.9)$ & 173/1244 (13.9) & $0.95(0.77-1.18)$ \\
\hline Seizures — no./total no. (\%) & 23/1171 (2.0) & $29 / 1244(2.3)$ & $0.79(0.45-1.38)$ \\
\hline \multicolumn{4}{|l|}{$\begin{array}{l}\text { Findings on cranial ultrasonography }- \\
\text { no./total no. }(\%)\end{array}$} \\
\hline Any intraventricular hemorrhage & 218/1112 (19.6) & $252 / 1184(21.3)$ & $0.91(0.78-1.08)$ \\
\hline $\begin{array}{l}\text { Grade III or IV intraventricular } \\
\text { hemorrhage }\end{array}$ & $23 / 1112(2.1)$ & $38 / 1184(3.2)$ & $0.64(0.38-1.06)$ \\
\hline Periventricular leukomalacia & 21/1112(1.9) & $27 / 1184(2.3)$ & $0.83(0.47-1.45)$ \\
\hline $\begin{array}{l}\text { Major congenital anomaly }- \text { no./total } \\
\text { no. }(\%)\end{array}$ & $47 / 1112(4.0)$ & $33 / 1184(2.7)$ & $1.51(0.97-2.33)$ \\
\hline
\end{tabular}

* Plus-minus values are means \pm SD. Except for intraventricular hemorrhage and periventricular leukomalacia (which were diagnosed centrally by three independent pediatric radiologists), data on complications are based on clinical diagnoses in the medical record.

${ }^{\dagger}$ The relative risk is given for a composite of intubation or chest compressions. 